\title{
Review \\ Condition-Based Monitoring and Maintenance: State of the Art Review
}

\author{
Ahad Ali ${ }^{1}$ and Abdelhakim Abdelhadi ${ }^{2, *(1)}$ \\ 1 A. Leon Linton Department of Mechanical, Robotics and Industrial Engineering, Lawrence Technological \\ University, Southfield, MI 48075, USA; sali@ltu.edu \\ 2 Masters of Engineering Management Program, Department of Engineering Management, Prince Sultan \\ University, Riyadh 11586, Saudi Arabia \\ * Correspondence: abdelhadi@psu.edu.sa
}

Citation: Ali, A.; Abdelhadi, A. Condition-Based Monitoring and Maintenance: State of the Art Review. Appl. Sci. 2022, 12, 688. https:// doi.org/10.3390/app12020688

Academic Editors: João Carlos de Oliveira Matias and Paolo Renna

Received: 18 December 2021

Accepted: 8 January 2022

Published: 11 January 2022

Publisher's Note: MDPI stays neutral with regard to jurisdictional claims in published maps and institutional affiliations.

Copyright: (C) 2022 by the authors. Licensee MDPI, Basel, Switzerland. This article is an open access article distributed under the terms and conditions of the Creative Commons Attribution (CC BY) license (https:// creativecommons.org/licenses/by/ $4.0 /)$.

\begin{abstract}
Manufacturing firms face great pressure to reduce downtime as well as maintenance costs. Condition-based maintenance (CBM) can be used to effectively manage operations and maintenance by monitoring detailed machine health information. CBM policies and the development of the mathematical models have been growing recently. This paper provides a review of the theoretical and practical development in the field of condition-based maintenance and its current advancements. Standard CBM platform could make it effective and efficient in implementation and performance improvement.
\end{abstract}

Keywords: maintenance; condition-based monitoring; artificial intelligence

\section{Introduction}

Condition monitoring is the process of observing a set of parameters and/or variables that indicate that the state of the system under investigation. It plays a significant role in the maintenance, management, and sustainable operations of various sectors, such as manufacturing industries [1-4], transportation [5,6], energy [7-9], natural resources [10-13], both natural and human-made disasters [14,15], and healthcare [16,17]. In most cases, sensors and/or micro-controllers are widely used to perform condition monitoring [18,19]. In particular, in this paper, our focus is to provide a comprehensive review on various condition monitoring approaches and their applications in the maintenance in manufacturing industries.

In terms of manufacturing industries, condition monitoring generally recommends a set of maintenance requirements in the event of failure or malfunctioning of the vital devices or equipment of the system concerned; thus, the entire process can also be termed as condition-based maintenance (CBM) [20-22]. It can be viewed as (i) a mechanism of preventive maintenance, thus effective in planning maintenance scheduling; (ii) a comprehensive tool for assessing both of the diagnostic and prognostic conditions; (iii) an assistive method in configuring system requirements and also enhancing the capability of conducting regular evaluation and/or maintenance operations; and (iv) a technique to optimize the operational availability of devices, equipment, and modules of various systems $[23,24]$. In general, it provides several advantages, such as (i) reducing downtime and maintenance expense by eliminating unnecessary maintenance; (ii) providing an early failure detection to increase asset availability, avoiding unnecessary downtime; (iii) supporting continuous improvement ensuring accurate and consistent response to developing conditions; (iv) providing better decision making for operations, engineering, and maintenance staff; (v) providing integration of control, safety, and maintenance environments; (vi) facilitating the opening of an operator's time to manage assets; (vii) enabling an organization to turn data into actionable and valuable information; (viii) evaluating the equipment activities 
and statistics, not normally maintained in repair logs; (ix) providing a repository to capture the conditions, rules, and other tacit knowledge; $(\mathrm{x})$ allowing the organization to retain intellectual property as the workforce changes; (xi) supporting safety and security to avoid major catastrophic disasters; and (xii) improving morale of the workforces and users [25-27]. Despite the above-mentioned advantages, it has some drawbacks, such as (i) the initial installation costs being even higher than the system under monitoring, and (ii) uncertainty associated with the failure of the condition monitoring devices [27-29].

The concept of CBM was developed in the 1940s; however, its significant utilization has been observed since the late 1990s [30]. It is also related to the technological advancements (in particular to electronics and communication) in the condition monitoring devices and propagation of the information to the system analyst [31,32]. It has become increasingly more important along with the progress in the field of automation engineering [33]. In order to synthesize the progress of CBM, we provide a literature review in Section 2, CBM-related research activities in the post-secondary institutes in Section 3, and finally concluding remarks and future research in Section 4.

\section{Literature Review}

The implementation of CBM is to be found in various applications, such as vibration modeling, sensor performance, signal processing, noise control, thermodynamic performance monitoring, lubricant oil, corrosion monitoring, non-destructive test, and inspection techniques (e.g., magnetic particle inspection, alternating current potential difference, ultrasonic, eddy current, radiography, acoustic emission) [34-37]. The selection of an appropriate CBM (and its optimization techniques) is always challenging and highly depends upon the system. We provide description of some of the commonly used such optimization techniques in CBM in the following sub-sections.

In general, a generic CBM system consists of three basic components: (i) data acquisition, (ii) data processing, and (iii) decision-making process [27,38]. Data are usually acquired by means of various sensors (e.g., electrical, electronic, mechanical, electromechanical). The acquired data are then processed in order to determine the health of the system under investigation. Numerous techniques are available, including the use of wavelet, neural network, feature recognition, statistical approaches, signal processing, and artificial intelligence [39]. Upon processing the data, it is then used in the decision-making process, such as in determining/predicting (i) remaining useful life, (ii) the confidence level, (iii) failure analysis, (iv) proactive maintenance steps, (v) cost/benefit analysis, (vi) downtime reduction, (vii) performance improvement strategy, (viii) maintenance scheduling, and (ix) health condition [40,41]. In some of the instances, a CBM system may not be effective, e.g., (i) unavailability of the data required in assessing the state of the system, and (ii) in some cases, the acquired data may be qualitative rather than quantitative in nature, which makes the assessment more complex.

\subsection{Analytical Hierarchical Approach}

The analytical hierarchical approach (AHP) is a structural approach that is one of the frequently used techniques. For example, (i) Bevilacqua and Braglia [42] developed an AHP in determining the maintenance strategy selection in an Italian oil refinery with five possible possibilities of preventive, predictive, condition-based, corrective, and opportunistic maintenance. The best maintenance policy was selected for each facility of the plants including sensitivity analysis to improve the effectiveness. Due to the subjectivity associated with AHP, it might fail to capture detailed uncertainties of the system. (ii) Li and Brown [43] showed an approach to minimize the weighted average system reliability index (WASRI) by ranking maintenance tasks on the basis of their marginal benefit-to-cost ratios, wherein the benefit was defined as improvement in WASRI. A prioritizing approach was used to achieve component and system reliability. (iii) Waeyenbergh and Pintelon [44] demonstrated a framework for integrating all of the available information within a company, including experience of maintenance workers to capture data through modern information 
and communication technology (ICT) by considering both of the computerized information and knowledge. However, the details about both the implementation and validation of the proposed framework were not described. (iv) Swanson [45] reported the relationship between maintenance strategies and performance and used factor analysis for developing maintenance strategies. Lastly, (v) Wang et al. [46] developed a two-stage prognosis model for optimum maintenance strategies that is based on a fuzzy AHP to evaluate different maintenance strategies (i.e., corrective maintenance, time-based preventive maintenance, condition-based maintenance, and predictive maintenance) for different types of equipment. In general, the applicability of AHP might be useful in selecting the maintenance process but limited in predicting the uncertainty associated with the system under surveillance.

\subsection{Markov Chain}

In general, failure is random in nature, and thus it is quite challenging to model. In this context, one of the most frequently used techniques is to employ the Markov chain (MC) method, which is even effective in modelling failure where such indications are not clear in the historical dataset. It is often used in different applications where greater uncertainties are generally expected. In [47], a semi-Markov decision process (SMDP) was developed for the maintenance policy optimization of condition-based preventive maintenance problems, demonstrating that the deterioration rate at each failure stage was the same, thus suggesting an optimal policy was a sort of dynamic threshold-type scheme. In [48], a MC-based algorithm was proposed for a deteriorating system for simultaneous optimization of parameters of condition-based preventive maintenance with an accumulated deterioration random failure. In a similar study, Hontelez et al. [49] developed optimum CBM policies using a discrete Markov decision method. In [50], a MC-based model using relevant condition predictor was proposed for reliability prediction for systems under condition-based maintenance.

\subsection{Feature-Based (Signal Processing) Approach and Wavelet and Model-Based Approaches}

Complex structures and/or systems often undergo damage/failure profiles that require non-stationary analysis techniques in order to be capable of detecting them [51-53]. It is of critical interest to monitor these dynamic signals from inherent structural energy changes and vibration that reflect due to the damage/failure itself. Traditional Fourier series analysis models are not appropriate since they require stationary data. Multi-scale, time-frequency analysis techniques such as wavelets can be applied to provide a robust framework for efficient analysis of such non-stationary processes [54,55]. Wavelet transforms have been studied since the 1950s by mathematicians, but it has only been in the last 10 years that they have made huge advancements in the engineering and signal processing community [6]. The wavelet transform is an operation that transforms a signal of interest with scaled and delayed from original signal to threshold signal [51]. Wavelet transformations are used for time-frequency representation of the signals for uncertainly/nonstationary using respective sampling theory. In signal monitoring and analysis, wavelet is also a very useful tool for failure prediction. On the basis of the signal from the sources, the different models could be realized for failure prediction. Wavelet and model/feature-based approaches are commonly used for failure prediction/condition-based monitoring and maintenance on the basis of the sensor and/or controller data.

In another application of wavelet, an innovative scheme for the machinery condition monitoring was presented on the basis of the wavelet modulus maxima representation [56]. Signal decomposition technique is applied to extract gear motion signal, and then wavelet transform modulus maxima is utilized to define fault growth parameter (FGP). CBM with the vibration management enhancement program is used by the U.S. Army National Guard, U.S. Army Special Operations, and U.S. Army TMDE demonstration program [57]. In another study, Wang et al. developed robust health evaluation of gearbox for tooth failure with wavelet decomposition. A study was conducted for CBM in punching-blanking of sheet metal using statistical, artificial intelligence (AI), and model-based approaches [58,59]. 
Special attention was given to inherent assumptions and other sources of inaccuracy, demonstrating how the signature of the force-displacement relation changes significantly with increasing tool wear in a typical configuration of sheet steel blanking. Kuravsky et al. [60] shows capability of wavelet transforms including relaxation neural networks for technical diagnostics and monitoring.

Different types of signal processing are also used for data processing from the sensor system. A comparative study of various classification algorithms was carried out for fault diagnosis of electric motors using different types of signals [61]. Experimental evaluation with the relative performances of five classifiers using five types of steady-state signals were conducted on the basis of three kinds of performance evaluation strategies: trainingtest, cross-validation, and similar measure. The raw signals are collected, and features are extracted from the collected signals; the extracted features are classified using the five classification algorithms, and an overall comparison of the five classifiers is discussed. In another study, a multi-criteria decision model is presented to determine inspection intervals of condition monitoring based on delay time analyses to simultaneously determine inspection intervals for condition monitoring regarding the failure behavior of equipment to reduce cost and downtime [62]. A decision model application in an electric power distribution company was presented. This application highlighted the suitability and practicality of the model. A tool condition monitoring approach is demonstrated in an end-milling operation based on the vibration signal collected through a low-cost, microcontroller-based data acquisition system [63]. Marinescu et al. used a time-frequency acoustic emission (AE)-based monitoring technique to identify work piece surface malfunctions in milling with multiple teeth cutting simultaneously [64]. New methods for supervising cutting processes were proposed with multiple teeth cutting simultaneously by use of AE signals backed-up by force data. Sometimes, hybrid approaches are used since single approach might not represent all uncertainties/non-stationary processes of the system or product. These wavelet-based models are very powerful in terms of modelling failure behavior if the proper signal could be collected with necessary accuracy.

\subsection{Artificial Intelligence}

Since failures involve uncertainties/non-stationary processes, various artificial techniques (i.e., neural network, genetic algorithm, fuzzy logics, expert systems) are frequently used for condition assessment and decision making. Applications of artificial intelligence to CBM to widen the scope of expert systems and to use it for machine diagnosis have been presented [65], and when administered properly through AI, can prevent accidents and increase the resale value of machines.

Hasan et al. [66] proposed an explainable AI-based approach for bearing fault diagnosis under variable speed and load conditions. A five-stage scheme is suggested to identify faults in the observed bearing signals: fast discrete orthogonal Stockwell transformation (FDOST) wrapper-based feature selector-Boruta, the Spearman's rank correlation coefficient (SRCC), the k-nearest neighbor (k-NN) algorithm, and the Shapley additive explanation (SHAP) for model interpretation.

Garcia et al. [67] provided the SIMAP Intelligent System for predictive maintenance to the health condition monitoring of a wind-turbine gearbox by taking account the information coming in real time from different sensors and other information sources. It is concluded that artificial intelligence and modelling techniques are adequate for reaching the main goals of the predictive maintenance strategy. Kothamasu et al. [68] presents an approach for incorporating population characteristic information and suspended condition trending data of historical units into prognosis using a feed-forward neural network, Kaplan-Meier estimator, and a degradation-based failure probability density function (PDF) estimator. The comparative model is used with a conventional time series prediction model to predict more accurately further ahead than similar methods that do not include population characteristics and/or suspended data in prognosis. In another combinational modeling (qualitative physics and product modeling) for product maintenance, model- 
based maintenance in terms of inspection, monitoring, diagnosis, and planning based on functional, behavioral, and state-of-the-art models are discussed. Effective integration on AI in CBM will enhance usability and predictability of the failure systems. Jiang et al. [69] proposed a novel method based on improved convolution bearing fault diagnosis using neural network and transfer learning. The transfer learning (TL)-based framework can save a significant amount of time in the course of task completion [70,71]. This method was adopted by Hasan et al. [72] to identify bearing faults under certain fault sizes. Zheng et al. [73] used multi-synchro squeezing S-transform for fault diagnosis in rolling bearings.

Genetic algorithms and fuzzy logic are used to model uncertainties/non-stationary processes. Since there are lot of uncertainties in the maintenance systems and sometimes the systems are not well structured, the fuzzy techniques would be more applicable for failure prediction and condition assessment [74,75]. Optimizing maintenance and repair policies were presented with a combination of genetic algorithms and Monte Carlo simulation within the context of plant logistic management on the choice of maintenance and repair strategies for an industrial plant, in the face of reliability and economic constraints. Monte Carlo simulation was used for economic analysis [76]. In another study, Marseguerra et al. came up with a similar hybrid technique with stress-dependent degradation processes for load sharing components and of a reduced number of maintenance workers available on site [77]. Sharma uses an approach based on fuzzy linguistic modeling to select the most effective and efficient maintenance strategy with three input parameters (historical data, present data, and competence of data). Although it uses a fuzzy set and rule-based system, it may not provide a complete scenario [78]. A fuzzy multiple criteria decision-making (MCDM) evaluation methodology is used for the cost-effective maintenance approach [79]. A neuro-fuzzy modelling approach for CBM to focus on model comprehensibility with effective decision aid for domain experts with Kullback-Leibler mean information to evaluate and refine tuned rules with a couple of real-world applications in bearing failure and aircraft engine failure [66]. A condition-based preventive maintenance arrangement was presented for thermal power plants using a hybrid Petri net modelling method coupled with fault-tree analysis and parameter trend to perform early failure detection and isolation [80]. In a similar study, a procedure for diagnosis and CBM was provided for power transformers [81]. Recurrent neural nets and the neuro-fuzzy systems approach were developed for managing the CBM of a combined-cycle power plant at a medium-sized Italian refinery. In some situations, genetic algorithms and/or fuzzy logic could be used for condition mentoring and maintenance. There are no certain guidelines when it should be used. Although artificial intelligence is used frequently for condition monitoring and prediction, there are some reservations in applications [82]. To improve the anti-noise performance of the fault diagnosis model and the denoising performance, ref [83] studied a joint learning mechanism. Researchers have relied on several signal processing techniques, such as fast Fourier transformation (FFT) [84], empirical mode decomposition (EMD) [85], energy entropy (EE) [86], wavelet packet decomposition (WPD) [87], empirical wavelet transformation (EWT) [88], variation mode decomposition (VMD) [89].

\subsection{Remaining Useful Life}

Remaining useful life (RUL) is used both in theory and applications. Engineers use it mostly when they have to decide whether to perform maintenance or to delay it due to production requirements [90]. Most often, RUL is used for later life of equipment in wearout period. Condition assessment is used commonly to predict remaining useful life (RUL) of the equipment or systems. A prognostic approach is presented to estimate the remaining useful life of gas turbine engines before their next major overhaul based on historical health information [91,92]. A combined regression including both linear and quadratic models is proposed to predict the remaining useful life. Two-stage prognostic model is used for the life of a piece of production equipment, with the first stage as the normal working stage and the second stage as the failure delay period [93-96]. With the help of condition monitoring, the equipment hidden defects may be detected for maintenance planning purposes; the 
prediction of the second stage; and, more importantly, the residual life. Artificial neural network-based prediction methodology has been developed for remaining useful life of rotating machinery [97]. Tian et al. developed a neural network approach for remaining useful life prediction, utilizing both failure and suspension histories of age and conditionmonitoring data from the equipment [98]. In another methodology, Technical Condition Index (TCI) is used for remaining useful life of natural gas export compressors [99]. There are greater challenges to select or develop appropriate prediction algorithm since it is on a case-by-case basis and environment-related.

\subsection{Deteriorating Systems}

Deterioration is a process where a system deteriorates continuously due to usage or age. Important parameters of the system gradually worsen if left unattended, and the process leads to deterioration failure [100]. Since deterioration is unpreventable, an efficient maintenance policy can reduce the system failure. Many studies have been conducted for condition-based maintenance in deteriorating systems. Much of the focus of these investigations has been in the failure prediction using different methodologies. A CBM policy for stochastically deteriorating systems was proposed to focus on analytical modelling of a condition-based inspection/replacement policy for the same [101]. A mathematical model was derived for the maintained system cost, supported by the existence of a stationary law for the maintained system state. In another study, a condition-based maintenance policy for a two-unit deteriorating system was presented [102]. Each unit's gradual deterioration and monitoring was based on sequential non-periodic inspections with a stochastic model for optimal maintenance performance. Closed-form expressions of system availability are derived when the device undergoes both deterioration and Poisson failures with a polynomial to solve for the optimal inspection interval [103]. A quantitative approach for maintenance inspection scheduling and planning was presented with three main modules: risk estimation module, risk evaluation module, and maintenance planning module [104,105]. A condition-based replacement and spare provisioning policy is presented for deteriorating systems with uncertain deterioration to failure with a simulation method and the genetic algorithm for minimizing the cost rate. A case study is provided for optimizing the maintenance scheme of haul truck motors and the order of the spare motors at Cardinal River Coals in Canada. Lin et al. [106] presented a simulation model for maintaining equipment performance with integrated equipment CBM and field activity of an elevator service provider. A simulation modelling of repairable multi component deteriorating systems was developed for on-condition maintenance optimization [107] to minimize the expected total system cost over a given mission time. A non-repairable single component, subjected to stochastic degradation, was first considered, and the degradation model was then generalized to multi-component repairable systems. The modeling techniques of failure prediction are varied on the basis of the rate of the failures and surrounding parameters. Although a statistically based methodology is commonly used, the integrated modeling approach with different methods might be more suitable to address real-world uncertainties.

\subsection{Oil Condition Monitoring}

Oil condition monitoring is used to measure engine oils, lubricating oils, and other fluids for detection of lubricant engine wear and related problems to reduce downtime [108]. Continuous oil condition monitoring in machineries and rotary systems is one of the rapidly growing areas for both predicting and preventing their failure. Ahmadi and Mollazade [109] demonstrated the effectiveness of oil condition monitoring techniques in determining the best oil for Dump Truck HD325-5 (used in transportation of minerals). Similar oil condition monitoring systems are available in the literature [110-112]. Du and Zhe [113] used a high-throughput inductive pulse sensor for online oil debris monitoring. In another study, Xia and Huo [114] developed oil monitoring methods based on information theory. 
Mackos et al. [115] developed a fluid quality sensor to monitor the oil quality applicable for commercial, military, and off-highway vehicles.

\subsection{Early Warning}

Early warning system is used to send warnings for the problem at the beginning or at more serious stages. Such a system can have an enormous impact where higher safety is involved, e.g., nuclear power plants. Some examples include: (i) Zhang et al. [116], who developed an early warning system using "asymptotical local" approach and applied it to a CBM system. It was based on characterizing a system through an identified model and then monitoring its changes. This approach demonstrated its effectiveness for detecting small changes, and also its robustness with respect to the bias of nominal model identification. However, sometimes it would not be possible to have knowledge about the system parameter to detecting changes; thus, a nominal model could be employed instead. (ii) A robust condition monitoring for early detection was developed of broken rotor bars in induction motors [117]. (iii) A statistical approach was used in process control as part of early defect identification [118,119]. (iv) Early warning systems using failure modes analysis was used for dam safety monitoring [120-122], etc.

\subsection{K-Out-of-N System}

$\mathrm{K}$-out-of- $\mathrm{N}$ is used when there is uncertainty of the lifetime. If at least $\mathrm{K}$ numbers of components are in good condition out of $\mathrm{N}$ components in a system, this is known as a K-out-of-N system. Smidt-Destombes et al. [123] suggested maintenance operation if the quantity of good components were less than $\mathrm{K}$, wherein all of the components were identical and repairable as well. Another study focused on the methodology of a condition-based preventive maintenance as part of the overall asset management strategy. A maintenance monitoring system subject to false alarms and failure to alarm used K-outof-N systems with multiple dependent monitors on the basis of the probability matrix being weak MLR (weak multivariate monotone likelihood ratio) [124]. On the basis of their optimal procedure of a monitoring system, a K-out-of-N system can identify an optimal decision quickly. There have been studies conducted for maintenance, spare part inventories, and repair capacity with their interaction for a K-out-of-N system with wearout [125]. Order-restricted hypothesis tests are considered for making the decision about the usual K-out-of-N model or the general sequential K-out-of-N model for given data [126]. Simultaneous maximum likelihood estimation is considered for the model parameters and the distribution parameters with a flexible location-scale family. Many researchers have extended the concept of binary K-out-of-N system to multi-state K-out-of-N systems.

\subsection{Reliability-Centered Predictive Maintenance}

Reliability-centered maintenance (RCM) is a systematic approach to ensure effective and efficient use of the assets in the designed operating conditions. It focuses on effective and cost-efficient preventive and predictive maintenance programs. A reliability-centered predictive maintenance (CBPM) policy is proposed for a continuously monitored system subject to degradation due to the imperfect maintenance [127]. It is assumed that the system hazard rate is a known function of the system condition and then can be derived directly through CBPM. A hybrid hazard rate recursion rule based on the concept of age reduction factor and hazard rate increase factor is built up to predict the evolution of the system reliability in different maintenance cycles. The optimal reliability threshold is determined by minimizing the cumulative maintenance cost per unit time in the residual life of the system, which is based on simulation. In another study, a reliability-centered maintenance strategy was used on the basis of maintenance-free operating period philosophy and total lifetime operating cost analysis for the aero industry [128]. RCM can also address the life cycle cost. A design of operational vehicle maintenance program based on life cycle cost and reliability-centered maintenance is proposed in military applications [129]. The costbased performance measured was used in another study wherein a prototype cost model of 
functional check decisions was used in reliability-centered maintenance [130]. RCM is more commonly applied, being oriented with large number of details of personal involvement.

\subsection{Web and Wireless in CBM}

Web-enabled remote monitoring is also used for condition-based maintenance [131]. It can collect data through sensors remotely and transfer the critical information for further processing and analysis. XML and web technology could be used to integrate remote equipment, devices, installations, etc., for data transfer and decision making. Ali et al. [132] introduced the emerging field of e-maintenance and its critical elements. Furthermore, performance assessment and prediction tools are introduced for continuous assessment and prediction of a particular product's performance, ultimately enabling proactive maintenance to prevent a machine from breakdowns. Kwon et al. [133] discussed the current trends in industry, which include an integration of information and knowledge-based network with a manufacturing system, which coined a new term, e-manufacturing, and focused on the accessibility to a remotely located system and having the means of responding to a changing environment. Within the framework of the web-enabled robotic system, it focuses on the remote maintenance schemes with an emphasis on condition-based maintenance strategies with mathematical modelling of system availability in the subsystems of the robot. Marquez et al. [134] developed algorithms to detect gradual failure in railway turnout with an RCM2 approach to the management of switch and crossing maintenance and demonstrated the approach using data from tests on a commonly found point mechanism by adopting a Kalman filter for pre-processing the data collected during tests. In the same year, Pedregal et al. [135] used RCM2 predictive maintenance of railway systems based on unobserved component models. Tiwari et al. [136] developed a wireless sensor network for machinery condition-based maintenance (CBM) in small machinery spaces using commercially available products. A LabVIEW graphical user interface is used for signal processing, including FFT, various moments, and kurtosis using a wireless CBM sensor network on a heating and air conditioning plant. Tiwari et al. [137] presented a wireless sensor network for machinery CBM using commercially available products, including a hardware platform, networking architecture, and medium access communication protocol on a Heating and Air Conditioning plant. Djurdjanovic et al. [138] developed an infotronics based prognostic approach for product performance degradation assessment and prediction. They called it "Watchdog Agent", and it is used for multi-sensor assessment and prediction of machine or process performance and can be utilized to realize predictive CBM, CPLM, and identification of components with significant remaining useful life. All the related work on web and remote systems is limited with a firewall of information since different applications need different types of protocols for communication. Since sensors have the limited of transferring data, web-sensors might be helpful to transfer data from source location to remote decision maker location. These kinds of web sensors might have a large impact in monitoring, especially in environment-related condition monitoring.

\subsection{Cluster-Based}

Almomani et al. [139] advanced a cluster framework for planning preventive maintenance actions using the Group Technology (GT) concept. Gong et al. [140] used cluster analysis (CA) to establish the qualitative analysis models on the basis of the two-channel and differential dielectric spectroscopy (TD-DES) data and Fourier transform infrared (FTIR) spectroscopy data of the in-service lubricants. Da-Silva et al. [141] utilized most of CA techniques while clustering the chemical analysis of lubricant. In a recent study, CA was utilized to confirm fuel dilution in an engine oil [142]. A fuzzy clustering approach was proposed as a lubricant system fault diagnosis framework using fuzzy sets theory on the system characteristics [143]. 


\subsection{Standardization of CBM Systems}

Although CBM systems are well known and are used in many applications with significant improvement, there is no consensus about universal standard. There are barriers in platform, industry sectors, IP issues, etc., to coming up with an open system. Thurston and Lebold [144] discussed the development of open system architecture for CBM and defined the requirements for a general CBM architecture and the framework of the distributed architecture. It was also being evaluated for transition by both Army and Nany programs. The changing role of maintenance is presented from the perspective of life cycle management and identified technical issues of maintenance [145]. A generic model was presented with the total productive maintenance (TPM) and CBM basics, in conjunction with ecology-oriented manufacturing (EOM) and $5 \mathrm{~S} f$ in attaining organizational equipment maintenance goals [146]. A systematic implementation framework coupled with the standard tools, techniques, and practices has been designed in a large semiconductor manufacturing company. Another generic CBM architecture was developed across different domains with a combined data fusion/data mining-based architecture [147]. Data fusion is extensively used in defense applications with an automated process of combining information from several sources in order to make decisions regarding the state of an object. Whereas data mining seeks unknown patterns and relationships in large datasets, the methodology is used to support data fusion and model generation at several levels. In the architecture, methods from both these domains analyze CBM data to determine the overall condition or health of a machine. This information is then used by a predictive maintenance model to determine the best course of action for maintaining critical equipment. Banjevic et al. [148] used Cox's PHM (prognostic and health management) with a Weibull baseline hazard function, and time-dependent stochastic covariates are used to describe the failure rate of the system with proposed structure of the decision-making software EXAKT. Sundberg [149] provides the economical aspect of condition monitoring and the strategically important considerations inside the maritime industry. Web and agent technologies in condition monitoring and the maintenance of mechanical and electrical systems are presented [150]. The OSA-CBM (Open System Architecture Condition-Based Maintenance) layers are used for the analysis of the reviewed work. Different architectures, methodologies, and tools are proposed by the researchers for the development of agent systems. Few findings report the use of mobile devices. Since the mobile/handheld devices spread markets recently, the effectiveness of those types of equipment for CBM to reduce downtime is unaddressed. The limited methodologies are available for the applications of mobile devices. There is a great potential to use handheld device injunction with web-based system for wider integration and effective use for decision making. It might give easy access remotely since the technologies are evolving faster than ever. Web-sensor open platform could be application also.

\section{University Research Related to CBM}

As people around the world are becoming increasingly more aware of the applications of CBM, they are taking interest in developing new technologies and strategies and are coming up with new management tools related to CBM. Most of this research around the world takes place in universities and defense. In the United States, the Department of Defense (DoD) has invested a large amount in the field of CBM. Their main focus is to meet the warfighter expectation while making every effort to conduct cost-effective sustainment operations. Thus, on 7 November 2007, DoD established a policy for CBM+, which provides an integrated strategy for deployment of enabling technologies, processes, and procedures that focus on a broad range of weapon system sustainment improvements. $\mathrm{CBM}+$ was originally developed as a DoD initiative to provide a focus for a broad variety of maintenance improvements that would benefit both the maintainer and the warfighter [151]. It was established to expand upon condition-based maintenance (CBM) and encompasses other technologies, processes, and procedures that enable improved maintenance and logistics practices. The CBM+ Action Group developed a "CBM+ DoD Guidebook" as an 
information reference and tool to assist logistic managers with $\mathrm{CBM}+$ project development, implementation, and execution.

Defense Acquisition University, which provides learning and consulting for acquisition programs and projects, provides training on $\mathrm{CBM}+$ business case analysis [152]. The Condition-Based Maintenance plus (CBM+) module provides the learner with an overview and introduction to Depot Maintenance Management and Operations needed in DoD systems [153]. The Applied Research Laboratory at the Pennsylvania State University (ARL Penn State) is using a systems approach for CBM. This is done by using a hierarchical architecture for developing and implementing health assessment systems. Here, in this hierarchy, a system is considered right from the top level to the lowest level of components where the failure originates. This hierarchical architecture consists of six levels: material, element, component, subsystem, system, and plant platform. They have been working in this field since 1994 and have established themselves as the world leader in CBM mechanical systems. Their projects cover various CBM issues from materials to decision support. The Systems and Operations Automation (SOA) Division of the ARL Penn State addresses the emerging fields of condition-based maintenance (CBM) and advanced sensing and control. The division provides valuable research and development efforts to support the U.S. Department of Defense and U.S. industry. It uses a number of specialized tools and facilities focused on condition-based maintenance such as mechanical diagnostic test bed, diesel-enhanced mechanical diagnostic test bed, lubrication system test bench, bearing prognostics test rig, torsional test rig, ball and V-ring test stand, battery prognostics test bench, complex systems monitoring features toolbox, and systems integration and technology transfer (SITT) facility [154].

A lot of research is being done at the University of South Carolina (USC), in which emphasis has been given to collect and warehouse data and formulate requirements for a move towards CBM. Their CBM Research Centre has supported the U.S. Army by conducting research to support a timely and cost-effective aircraft maintenance program. The CBM program at USC combines comprehensive research with a multi-faceted methodology to strive towards continued success by the U.S. Army's aviation division. The CBM test facilities include a full-scale drive train test that stands capable of testing several platforms such as the U.S. Army Apache, Blackhawk, and Chinook helicopters [155]. At the University of Toronto, Canada [156], the research and development in the Vibration Monitoring, Signal Processing and CBM Laboratory focuses on the development of effective fault detection and diagnostic schemes on the basis of analysis and modelling of vibration data for CBM purposes. Moreover, CBM software developed at the University of Toronto, EXAKT, is quite well known in the industry for maintenance optimization. Furthermore, at their Centre for Maintenance Optimization and Reliability Engineering (C-MORE), they employ proportional hazards modelling to pinpoint the risk factors that threaten the health of the asset from all signals obtained during health monitoring. This hazard estimate (the conditional probability of failure) is then blended with economic considerations to establish optimal CBM decisions. A large amount of research on maintenance, predictive failure, e-manufacturing, and industry applications with embedded system are conducted at the NSF Industry/University Cooperative Research Center on Intelligent Maintenance Systems with multi-campus collaboration (University of Cincinnati, University of Michigan-Ann Arbor, and Missouri University of Science and Technology).

At the Robotics Research Group at the University of Texas at Austin [157], researchers are working on a method for automatic condition-based maintenance (CBM) that is based on decision-making criteria. This is to enhance the reliability, safety, and maintainability of robot actuators or other variable duty cycle machines and to reduce the cost of their overall maintenance. They are currently developing a decision making CBM (DM/CBM) to overcome the problems of modern model-based CBM. They have created a software test that plays an important part in the development of decision-making software that also will be used as a guideline for future students who will perform CBM-related research. At the Centre for Operational Research and Applied Statistics (CORAS) of the University of 
Salford, Greater Manchester University, United Kingdom, the research team is working on CBM [158], having concentrated their attention to date on developing models of the decision aspect of condition monitoring with the aim of optimizing a criterion function of interest. They have used stochastic filtering and hidden Markov models to model predictions of the residual life of monitored engineering systems, and hence to provide cost effective decision support. The conditional residual life formulation using semi-deterministic stochastic filtering is perhaps the first of this kind in condition-based maintenance modelling, which has been followed by many others since. The research has closely collaborated with industry users and engineering departments at other universities [159].

Other than the above-mentioned universities, the following is a list of a few universities wherein over the past few years, CBM/reliability-related work has been conducted:

1. Intelligent Systems Laboratory, Department of Mechanical, Industrial, and Nuclear Engineering, University of Cincinnati, Cincinnati, $\mathrm{OH}$, USA.

2. Automation and Robotics Research Institute, Ft. Worth, Texas, USA.

3. Zhejiang University, China.

4. Luleå University of Technology, Sweden.

5. Malardalen University, Sweden.

6. University of Groningen, Groningen, The Netherlands.

7. Wichita State University, USA.

8. National Institute of Technology, Tiruchirappalli, India.

9. Reliability Engineering Centre, Indian Institute of Technology, Kharagpur, West Bengal, India.

10. Department of Agricultural Machinery, Faculty of Biosystems Engineering, University of Tehran, Iran.

11. Vaxjo University, School of Technology and Design, Sweden.

12. School of engineering, Cranfield University, Cranfield, England, United Kingdom.

13. Division of Industrial and Information Systems Engineering, Ajou University, South Korea.

14. Queensland University of Technology, Brisbane, Queensland, Australia.

15. Federal University of Rio Grande do Norte, Rio Grande do Norte, Brazil.

16. University of Teeside, Middlesbrough, United Kingdom.

17. Department of Industrial Engineering, University at Buffalo (SUNY), Amherst, USA.

18. NSF I/U Center for Intelligent Maintenance System, University of Cincinnati, University of Michigan-Ann Arbor and Missouri University of Science and Technology, USA.

19. Dipartimento di Energetica, Universita Politecnica delle Marche, via Brecce Bianche, Ancona, Italy.

20. Universidad Pontificia Comillas, Instituto de Investigacion Tecnologica, Santa Cruz de Marcenado, Spain.

21. School of Mechanical Engineering, Shanghai Jiao Tong University, Shanghai, China.

22. University of Wisconsin, Milwaukee, USA.

23. Department of Industrial and Systems Engineering, The Hong Kong Polytechnic University, Hong Kong.

24. Rensselaer Polytechnic Institute, Troy, New York, USA.

25. The Logistics and Maintenance Applied Research Center (LandMARC), Georgia Tech.

26. Reliability and Maintainability Center, University of Tennessee, Knoxville.

27. Center for Risk and Reliability (CRR), and The Center for Advanced Life Cycle Engineering (CALCE), University of Maryland College Park.

28. The Industry/University Cooperative Center for Quality and Reliability Engineering Research with Rutgers University, Arizona State University, and University of Arizona.

29. University of Iowa, USA.

30. Wind Energy Center, University of Massachusetts Amherst, USA.

\section{Concluding Remarks and Future Research}

This paper presents a review of different methods and applications on condition-based maintenance. The main purpose of this paper is to enlighten the field of CBM by providing 
a holistic view of the global approach to CBM. Even though CBM requires sophisticated technologies, there is a large amount of research being done as people are starting to realize its importance. However, there is still much more that can be done. This includes lagging in open architecture, limited mobile applications, barrier in industry-to-industry sectors, limited censuses on unique CBM platform, etc. By only determining the states for which the unit is replaced in order to gain the maximum maintenance cost (Markov decision process) or by modelling the system deterioration, which is stochastic and continuous, people are looking at a specific part of the system, not the system as a whole. A holistic view is more important than complex models and techniques. Figure 1 shows a generic CBM platform supervisory control and data acquisition (SCADA) proposed by [160]. Figure 2 shows a generic failure prediction approach.

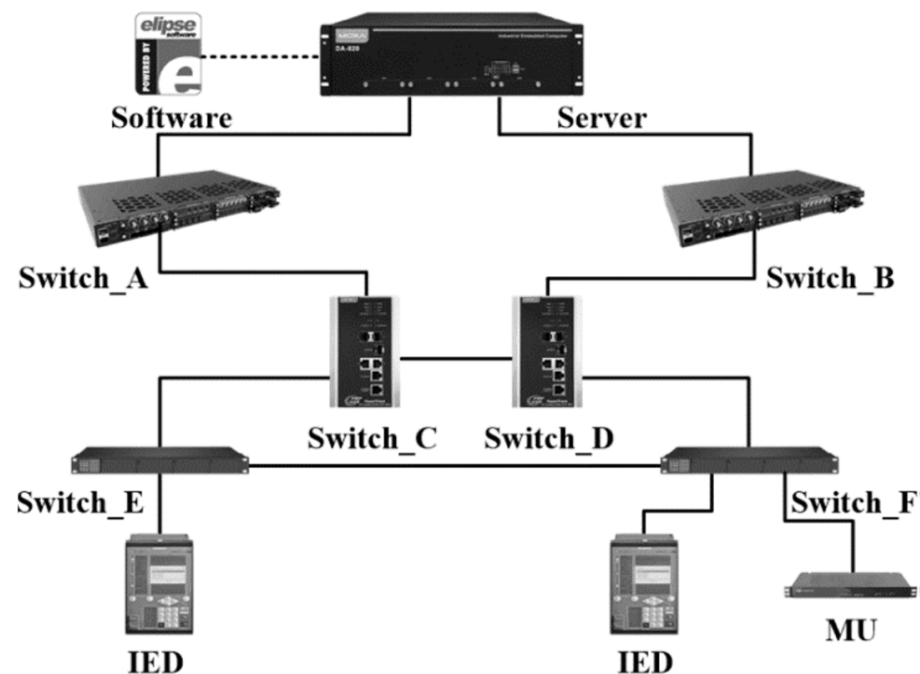

Figure 1. Schematic diagram illustrating a generalized form of CBM Platform.

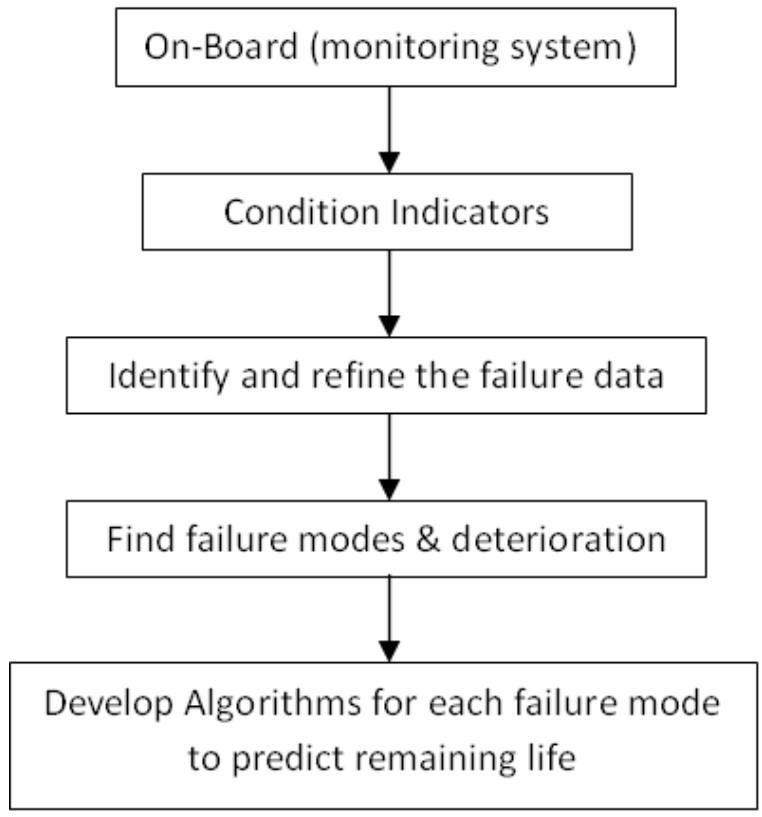

Figure 2. Failure algorithm steps.

As we go deep to the component level, we have to look it from a management point of view. A proper business case has to be developed that will take into consideration functionality, availability, economics, and reliability of the system. A proper study has to 
be performed well up front to address different issues while implementing CBM. These are the issues a proper business case must address. As we are approaching the end of the first decade of the 21st century, computers are becoming faster and a highly efficient electronic equipment, such as sensors are available in the market. There is a lot that we can be used from this industry that can be well implemented in the CBM field. A more focused approach is needed towards application of embedded electronics in CBM. The advancement in web technologies allows remotely located robots to be programmed, operated upon, and monitored for maintenance. However, the findings show that e-maintenance is still in its infancy stage. Artificial intelligence offers a number of methods and techniques that provide potential benefits if harnessed properly.

Author Contributions: Conceptualization, methodology, writing-original draft: A.A. (Ahad Ali). Writing-review and editing: A.A. (Abdelhakim Abdelhadi). All authors have read and agreed to the published version of the manuscript.

Funding: Authors would like to thank Prince Sultan University in Saudi Arabia for their financial support of this research.

Institutional Review Board Statement: Not applicable.

Informed Consent Statement: Not applicable.

Data Availability Statement: The data presented in this study are available in this article.

Conflicts of Interest: The authors declare no conflict of interest.

\section{References}

1. Li, Z.; He, Z.; Zi, Y.; Chen, X. Bearing condition monitoring based on shock pulse method and improved redundant lifting scheme. Math. Comput. Simul. 2008, 79, 318-338.

2. Cho, S.; Binsaeid, S.; Asfour, S. Design of multisensor fusion-based tool condition monitoring system in end milling. Int. J. Adv. Manuf. Technol. 2010, 46, 681-694. [CrossRef]

3. Lee, J.; Chen, Y.; Al-Atat, H.; Abuali, M.; Lapira, E. A systematic approach for predictive maintenance service design: Methodology and applications. Int. J. Internet Manuf. Serv. 2009, 2, 76-94. [CrossRef]

4. Wu, F.; Wang, T.; Lee, J. An online adaptive condition-based maintenance method for mechanical systems. Mech. Syst. Signal Process. 2010, 24, 2985-2995. [CrossRef]

5. Mei, T.X.; Ding, X.J. Condition monitoring of rail vehicle suspensions based on changes in system dynamic interactions. Veh. Syst. Dyn. 2009, 47, 1167-1181. [CrossRef]

6. Yella, S.; Dougherty, M.; Gupta, N.K. Condition monitoring of wooden railway sleepers. Transp. Res. Part C Emerg. Technol. 2009, 17, 38-55. [CrossRef]

7. Tian, Z.; Jin, T.; Wu, B.; Ding, F. Condition based maintenance optimization for wind power generation systems under continuous monitoring. Renew. Energy 2011, 36, 1502-1509. [CrossRef]

8. Amirat, Y.; Benbouzid, M.E.H.; Al-Ahmar, E.; Bensaker, B.; Turri, S. A brief status on condition monitoring and fault diagnosis in wind energy conversion systems. Renew. Sustain. Energy Rev. 2009, 13, 2629-2636. [CrossRef]

9. Wiggelinkhuizen, E.; Verbruggen, T.; Braam, H.; Rademakers, L.; Xiang, J.; Watson, S. Assessment of condition monitoring techniques for offshore wind farms. J. Sol. Energy Eng. Trans. ASME 2008, 130, 0310041-0310049. [CrossRef]

10. Sekhon, N.S.; Hassan, Q.K.; Sleep, R.W. Evaluating potential of MODIS-based indices in determining "snow gone" stage over forest-dominant regions. Remote Sens. 2010, 2, 1348-1363. [CrossRef]

11. Hassan, Q.K.; Bourque, C.P.-A. Spatial enhancement of MODIS-based images of leaf area index: Application to the boreal forest region of northern Alberta. Remote Sens. 2010, 2, 278-289. [CrossRef]

12. Akther, M.S.; Hassan, Q.K. Remote sensing-based estimates of surface wetness conditions and growing degree days over northern Alberta, Canada. Boreal Environ. Res. 2011, 16, 407-416.

13. Hassan, Q.K.; Bourque, C.P.-A.; Meng, F.-R. Application of Landsat-7 ETM+ and MODIS products in mapping seasonal accumulation of growing degree days at enhanced resolution. J. Appl. Remote Sens. 2007, 1, 013539. [CrossRef]

14. He, M.; Tao, Z.; Zhang, B. Application of remote monitoring technology in landslides in the Luoshan mining area. Min. Sci. Technol. (China) 2009, 19, 609-614. [CrossRef]

15. Chen, Y.; Feng, M.Q.; Tan, C. Bridge structural condition assessment based on vibration and traffic monitoring. J. Eng. Mech. 2009, 135, 747-758. [CrossRef]

16. Lin, C.; Lee, R.; Hsiao, C. A pervasive health monitoring service system based on ubiquitous network technology. Int. J. Med. Inform. 2008, 77, 461-469. [CrossRef] 
17. Pantelopoulos, A.; Bourbakis, N.G. Prognosis-a wearable health-monitoring system for people at risk: Methodology and modeling. IEEE Trans. Inf. Technol. Biomed. 2010, 14, 613-621. [CrossRef]

18. Mariño, P.; Poza, F.; Otero, S.; Dominguez, M.A. Reconfigurable industrial sensors for remote condition monitoring and modeling. IEEE Trans. Ind. Electron. 2010, 57, 4199-4208. [CrossRef]

19. Owen, T.H.; Kestermann, S.; Torah, R.; Beeby, S.P. Self powered wireless sensors for condition monitoring applications. Sens. Rev. 2009, 29, 38-43. [CrossRef]

20. Besnard, F.; Bertling, L. An approach for condition-based maintenance optimization applied to wind turbine blades. IEEE Trans. Sustain. Energy 2010, 1, 77-83. [CrossRef]

21. Prajapati, A.; Bechtel, J.; Ganesan, S. Condition based maintenance: A survey. J. Qual. Maint. Eng. 2012, 18, 384-400. [CrossRef]

22. Neugebauer, R.; Fischer, J.; Praedicow, M. Condition-based preventive maintenance of main spindles. Prod. Eng. 2011, 5, 95-102. [CrossRef]

23. Li, L.; You, M.; Ni, J. Reliability-based dynamic maintenance threshold for failure prevention of continuously monitored degrading systems. J. Manuf. Sci. Eng. Trans. ASME 2009, 131, 0310101-0310109. [CrossRef]

24. Feng, Q.; Peng, H.; Coit, D.W. A degradation-based model for joint optimization of burn-in, quality inspection, and maintenance: A light display device application. Int. J. Adv. Manuf. Technol. 2010, 50, 801-808. [CrossRef]

25. Peng, Y.; Dong, M.; Zuo, M.J. Current status of machine prognostics in condition-based maintenance: A review. Int. J. Adv. Manuf. Technol. 2010, 50, 297-313. [CrossRef]

26. Lee, J.; Ni, J.; Djurdjanovic, D.; Qiu, H.; Liao, H. Intelligent prognostics tools and e-maintenance. Comput. Ind. 2006, 57, 476-489. [CrossRef]

27. Jardine, A.K.S.; Lin, D.; Banjevic, D. A review on machinery diagnostics and prognostics implementing condition-based maintenance. Mech. Syst. Signal Process. 2006, 20, 1483-1510. [CrossRef]

28. Buswell, R.A.; Wright, J. Uncertainty in model-based condition monitoring. Build. Serv. Eng. Res. Technol. 2004, 25, 65-75. [CrossRef]

29. Pandian, A.; Ali, A. A Review of Recent Trends in Machine Diagnosis and Prognosis Algorithms. Int. J. Comput. Inf. Syst. Ind. Manag. Appl. 2010, 2, 321-329.

30. Wiseman, M. A History of CBM (Condition Based Maintenance). Available online: http://www.omdec.com/moxie/Technical/ Reliability/a-history-of-cbm.shtml (accessed on 7 March 2021).

31. Pecht, M.; Jaai, R. A prognostics and health management roadmap for information and electronics-rich systems. Microelectron. Reliab. 2010, 50, 317-323. [CrossRef]

32. Li, L.; Qian, Y.L.; Du, K.; Yang, Y.M. A fast development framework for condition-based maintenance systems. In Proceedings of the 2nd International Conference on Mechanical and Electronics Engineering (ICMEE), Kyoto, Japan, 1-3 August 2010; pp. V2-70-V2-74.

33. Verl, A.; Heisel, U.; Walther, M.; Maier, D. Sensorless automated condition monitoring for the control of the predictive maintenance of machine tools. CIRP Ann. Manuf. Technol. 2009, 58, 375-378. [CrossRef]

34. Oke, S.A. Condition based maintenance: Status and future directions. SA J. Ind. Eng. 2004, 15, 27-43. [CrossRef]

35. Mitchell, J.S. From vibration measurements to condition based maintenance seventy years of continuous progress. Sound Vib. 2007, 41, 62-78

36. Yuan, J.; Pan, H. Gearbox vibration signals processing based on auxiliary particle filter and its application in fault location. J. Comput. Inf. Syst. 2010, 6, 1225-1233.

37. Abdelhadi, A. Preventive Maintenance Grouping Using Similarity Coefficient Methodology; The University of Wisconsin-Milwaukee: Milwaukee, WI, USA, 2010.

38. Lee, J.; Abujamra, R.; Jardine, A.K.S.; Lin, D.; Banjevic, D. An integrated platform for diagnostics, prognostics and maintenance optimization. In Proceedings of the IMS International Conference on Advances in Maintenance and in Modeling, Simulation and Intelligent Monitoring of Degradations, Arles, France, 17-19 July 2004.

39. Reis, D.; Pati, N. Applications of artificial intelligence to condition-based maintenance. RAE Rev. Adm. Empresas 2000, 40, 102-107. [CrossRef]

40. Landryová, L.; Sikora, J.; Wagnerová, R. The learning path to neural network industrial application in distributed environments. Processes 2021, 9, 2247. [CrossRef]

41. Elwerfalli, A.; Alsadaie, S.; Mujtaba, I.M. Estimation of shutdown schedule to remove fouling layers of heat exchangers using risk-based inspection (RBI). Processes 2021, 9, 2177. [CrossRef]

42. Bevilacqua, M.; Braglia, M. The analytic hierarchy process applied to maintenance strategy selection. Reliab. Eng. Syst. Saf. 2000, 70, 71-83. [CrossRef]

43. Li, F.; Brown, R.E. A cost-effective approach of prioritizing distribution maintenance based on system reliability. IEEE Trans. Power Deliv. 2004, 19, 439-441. [CrossRef]

44. Waeyenbergh, G.; Pintelon, L. A framework for maintenance concept development. Int. J. Prod. Econ. 2002, 77, 299-313. [CrossRef]

45. Swanson, L. Linking maintenance strategies to performance. Int. J. Prod. Econ. 2001, 70, 237-244. [CrossRef]

46. Wang, L.; Chu, J.; Wu, J. Selection of optimum maintenance strategies based on a fuzzy analytic hierarchy process. Int. J. Prod. Econ. 2007, 107, 151-163. [CrossRef] 
47. Rao, P.N.S.; Naikan, V.N.A. An algorithm for simultaneous optimization of parameters of condition-based preventive maintenance. SAGE Publ. 2009, 8, 83-94.

48. Amari, S.V.; McLaughlin, L. Optimal design of a condition-based maintenance model. In Proceedings of the Annual Symposium Reliability and Maintainability, 2004-RAMS, Los Angeles, CA, USA, 26-29 January 2004; pp. 528-533.

49. Hontelez, J.A.M.; Burger, H.H.; Wijnmalen, D.J.D. Optimum condition-based maintenance policies for deteriorating systems with partial information. Reliab. Eng. Syst. Saf. 1996, 51, 267-274. [CrossRef]

50. Saranga, H.; Knezevic, J. Reliability prediction for condition-based maintained systems. Reliab. Eng. Syst. Saf. 2001, 71, 219-224. [CrossRef]

51. Deng, X.; Wang, Q.; Giurgiutiu, V. Structural health monitoring using active sensors and wavelet transforms. In Proceedings of the SPIE's 6th Annual International Symposium on Smart Structures and Materials, Newport Bench, CA, USA, 1-4 March 1999.

52. Shokravi, H.; Shokravi, H.; Bakhary, N.; Rahimian Koloor, S.S.; Petrů, M. Health Monitoring of Civil Infrastructures by Subspace System Identification Method: An Overview. Appl. Sci. 2020, 10, 2786. [CrossRef]

53. Wang, D.; Tsui, K.-L.; Miao, Q. Prognostics and Health Management: A Review of Vibration Based Bearing and Gear Health Indicators. IEEE Access 2018, 6, 665-676. [CrossRef]

54. Hall, S.R.; Conquest, T.J. The total data integrity initiative-Structural health monitoring, the next generation. In Proceedings of the USAF ASIP, San Antonio, TX, USA, 2-5 November 1999.

55. Jansen, M. Noise Reduction by Wavelet Thresholding; Springer: Berlin/Heidelberg, Germany, 2001.

56. Miao, Q.; Makis, V. An application of the modulus maxima distribution in machinery condition monitoring. J. Qual. Maint. Eng. 2005, 11, 375-387. [CrossRef]

57. Keller, J.A.; Branhof, R.; Dunaway, D.; Grabill, P. Examples of condition-based maintenance with the vibration management enhancement program. In Proceedings of the American Helicopter Society 61st Annual Forum, Grapevine, TX, USA, 1-3 June 2005.

58. Klingenberg, W.; de Boer, T.W. Condition-based maintenance in punching/blanking of sheet metal. Int. J. Mach. Tools Manuf. 2008, 48, 589-598. [CrossRef]

59. Wang, D.; Miao, Q.; Kang, R. Robust health evaluation of gearbox subject to tooth failure with wavelet decomposition. J. Sound Vib. 2009, 324, 1141-1157. [CrossRef]

60. Kuravsky, L.S.; Baranov, S.N. Technical diagnostics and monitoring based on capabilities of wavelet transforms and relaxation neural networks. Insight Non-Destr. Test. Cond. Monit. 2008, 50, 127-132. [CrossRef]

61. Niu, G.; Son, J.D.; Widodo, A.; Yang, B.S.; Hwang, D.H.; Kang, D.S. A comparison of classifier performance for fault diagnosis of induction motor using multi-type signals. Structural Health Monitoring 2007, 6, 215-229. [CrossRef]

62. Ferreira, R.J.P.; de Almeida, A.T.; Cavalcante, C.A.V. A multi-criteria decision model to determine inspection intervals of condition monitoring based on delay time analysis. Reliab. Eng. Syst. Saf. 2009, 94, 905-912. [CrossRef]

63. Zhang, J.Z.; Chen, J.C. Tool condition monitoring in an end-milling operation based on the vibration signal collected through a microcontroller-based data acquisition system. Int. J. Adv. Manuf. Technol. 2008, 39, 118-128. [CrossRef]

64. Marinescu, I.; Axinte, D. A time-frequency acoustic emission-based monitoring technique to identify workpiece surface malfunctions in milling with multiple teeth cutting simultaneously. Int. J. Mach. Tools Manuf. 2009, 49, 53-65. [CrossRef]

65. Heng, A.; Tan, A.C.C.; Mathew, J.; Montgomery, N.; Banjevic, D.; Jardine, A.K.S. Intelligent condition-based prediction of machinery reliability. Mech. Syst. Signal Process. 2009, 23, 1600-1614. [CrossRef]

66. Hasan, M.J.; Sohaib, M.; Kim, J.-M. An explainable ai-based fault diagnosis model for bearings. Sensors 2021, 21, 4070. [CrossRef]

67. Garcia, M.C.; Sanz-Bobi, M.A.; del Pico, J. SIMAP: Intelligent system for predictive maintenance application to the health condition monitoring of a wind turbine gearbox. Comput. Ind. 2006, 57, 552-568. [CrossRef]

68. Kothamasu, R.; Huang, S.H. Adaptive Mamdani fuzzy model for condition-based maintenance. Fuzzy Sets Syst. 2007, 158, 2715-2733. [CrossRef]

69. Jiang, F.; Shen, X.; Jiang, F.; Zhao, Z.; Cheng, S. A bearing fault diagnosis method based on improved convolution neural network and transfer learning. In Proceedings of the SPIE 12127, International Conference on Intelligent Equipment and Special Robots (ICIESR 2021), Qingdao, China, 12 December 2021. [CrossRef]

70. Hasan, M.J.; Islam, M.M.M.; Kim, J.M. Acoustic spectral imaging and transfer learning for reliable bearing fault diagnosis under variable speed conditions. Meas. J. Int. Meas. Confed. 2019, 138, 620-631. [CrossRef]

71. Hasan, M.J.; Sohaib, M.; Kim, J.-M. A multitask-aided transfer learning-based diagnostic framework for bearings under inconsistent working conditions. Sensors 2020, 20, 7205. [CrossRef] [PubMed]

72. Hasan, M.J.; Islam, M.M.; Kim, J.-M. Multi-sensor fusion-based time-frequency imaging and transfer learning for spherical tank crack diagnosis under variable pressure conditions. Measurement 2021, 168, 108478. [CrossRef]

73. Zheng, X.; Wei, Y.; Liu, J.; Jiang, H. Multi-synchrosqueezing S-transform for fault diagnosis in rolling bearings. Meas. Sci. Technol. 2020, 32, 25013. [CrossRef]

74. Cai, K.-Y. System failure engineering and fuzzy methodology: An introductory overview. Fuzzy Sets Syst. 1996, 83, 113-133. [CrossRef]

75. Chongfu, H. Fuzzy risk assessment of urban natural hazards. Fuzzy Sets Syst. 1996, 83, 271-282. [CrossRef]

76. Kitak, P.; Belak, L.; Pihler, J.; Ribič, J. Maintenance management of a transmission substation with optimization. Appl. Sci. 2021, 11, 11806. [CrossRef] 
77. Marseguerra, M.; Zio, E.; Podofillini, L. Condition-based maintenance optimization by means of genetic algorithms and Monte Carlo simulation. Reliab. Eng. Syst. Saf. 2002, 77, 151-166. [CrossRef]

78. Sharma, R.K.; Kumar, D.; Kumar, P. FLM to select suitable maintenance strategy in process industries using MISO model. J. Qual. Maint. Eng. 2005, 11, 359-374. [CrossRef]

79. Al-Najjara, B.; Alsyouf, I. Selecting the most efficient maintenance approach using fuzzy multiple criteria decision making. Int. J. Prod. Econ. 2003, 84, 85-100. [CrossRef]

80. Marseguerra, M.; Zio, E. Optimizing maintenance and repair policies via a combination of genetic algorithms and Monte Carlo simulation. Reliab. Eng. Syst. Saf. 2000, 68, 69-83. [CrossRef]

81. Zając, M. The model of reducing operations time at a container terminal by assigning places and sequence of operations. Appl. Sci. 2021, 11, 12012. [CrossRef]

82. van Houten, F.J.A.M.; Salomons, O.W.; Tomiyamaz, T. Product modelling for model-based maintenance. Ann. CIRP 1998, 47, 123-128. [CrossRef]

83. Wang, H.; Liu, Z.; Peng, D.; Cheng, Z. Attention-guided joint learning CNN with noise robustness for bearing fault diagnosis and vibration signal denoising. ISA Trans. 2021. [CrossRef] [PubMed]

84. Shao, S.-Y.; Sun, W.-J.; Yan, R.-Q.; Wang, P.; Gao, R.X. A deep learning approach for fault diagnosis of induction motors in manufacturing. Chin. J. Mech. Eng. 2017, 30, 1347-1356. [CrossRef]

85. Ali, J.B.; Fnaiech, N.; Saidi, L.; Chebel-Morello, B.; Fnaiech, F. Application of empirical mode decomposition and artificial neural network for automatic bearing fault diagnosis based on vibration signals. Appl. Acoust. 2015, 89, 16-27.

86. Zhao, L.-Y.; Wang, L.; Yan, R.-Q. Rolling bearing fault diagnosis based on wavelet packet decomposition and multi-scale permutation entropy. Entropy 2015, 17, 6447-6461. [CrossRef]

87. Qiao, Z.; Liu, Y.; Liao, Y. An improved method of EWT and its application in rolling bearings fault diagnosis. Shock Vib. 2020, 2020, 1-13. [CrossRef]

88. Gu, R.; Chen, J.; Hong, R.; Wang, H.; Wu, W. Incipient fault diagnosis of rolling bearings based on adaptive variational mode decomposition and Teager energy operator. Measurement 2020, 149, 106941. [CrossRef]

89. Cheng, Y.; Lin, M.; Wu, J.; Zhu, H.; Shao, X. Intelligent fault diagnosis of rotating machinery based on continuous wavelet transform-local binary convolutional neural network. Knowl.-Based Syst. 2021, 216, 106796. [CrossRef]

90. Jarrell, D.; Sisk, D.; Bond, L. Prognostics and Condition Based Maintenance (CBM)—A Scientific Crystal Ball; Pacific Northwest National Laboratory: Richland, WA, USA, 2002.

91. Yang, S.K. A condition-based preventive maintenance arrangement for thermal power plants. Electr. Power Syst. Res. 2004, 72, 49-62. [CrossRef]

92. Setayeshmehr, A.; Akbari, A.; Borsi, H.; Gockenbach, E. A procedure for diagnosis and condition based maintenance for power transformers. In Proceedings of the 2004 IEEE International Symposium on Electrical Insulation, Indianapolis, IN, USA, 19-22 September 2004; pp. 504-507.

93. Ciarapica, F.E.; Giacchetta, G. Managing the condition-based maintenance of a combined-cycle power plant: An approach using soft computing techniques. J. Loss Prev. Process Ind. 2006, 19, 316-325. [CrossRef]

94. Li, Y.G.; Nilkitsaranont, P. Gas turbine performance prognostic for condition-based maintenance. Appl. Energy 2009, 86, $2152-2161$. [CrossRef]

95. Wang, W. A two-stage prognosis model in condition based maintenance. Eur. J. Oper. Res. 2007, 182, 1177-1187. [CrossRef]

96. Mahamad, A.K.; Saon, S.; Hiyama, T. Predicting remaining useful life of rotating machinery based artificial neural network. Comput. Math. Appl. 2010, 60, 1078-1087. [CrossRef]

97. Nystad, B.H.; Rasmussen, M. Remaining useful life of natural gas export compressors. J. Qual. Maint. Eng. 2010, 16, 129-143. [CrossRef]

98. Tian, Z.; Wong, L.; Safaei, N. A neural network approach for remaining useful life prediction utilizing both failure and suspension histories. Mech. Syst. Signal Process. 2010, 24, 1542-1555. [CrossRef]

99. Sim, S.H.; Endrenyi, J. A failure-repair model with minimal and major maintenance. IEEE Trans. Reliab. 1993, 42, 134-139. [CrossRef]

100. Grall, A.; Berenguer, C.; Dieulle, L. A condition-based maintenance policy for stochastically deteriorating systems. Reliab. Eng. Syst. Saf. 2002, 76, 167-180. [CrossRef]

101. Castanier, B.; Grall, A.; Berenguer, C. A condition-based maintenance policy with non-periodic inspections for a two-unit series system. Reliab. Eng. Syst. Saf. 2005, 87, 109-120. [CrossRef]

102. Chen, D.; Trivedi, K.S. Closed-form analytical results for condition-based maintenance. Reliab. Eng. Syst. Saf. $2002,77,43-51$. [CrossRef]

103. Khan, F.I.; Haddara, M.M. Risk-based maintenance (RBM): A quantitative approach for maintenance/inspection scheduling and planning. J. Loss Prev. Process Ind. 2003, 16, 561-573. [CrossRef]

104. Wang, L.; Chu, J.; Mao, W. A condition-based replacement and spare provisioning policy for deteriorating systems with uncertain deterioration to failure. Eur. J. Oper. Res. 2009, 194, 184-205. [CrossRef]

105. Banjevic, D. Remaining useful life in theory and practice. Math. Stat. 2008, 69, 337-349. [CrossRef]

106. Lin, Y.; Hsu, A.; Rajamani, R. A simulation model for field service with condition-based maintenance. In Proceedings of the Winter Simulation Conference, San Diego, CA, USA, 8-11 December 2002; pp. 1885-1890. 
107. Barata, J.; Soares, C.G.; Marseguerra, M.; Zio, E. Simulation modeling of repairable multi-component deteriorating systems for on condition maintenance optimization. Reliab. Eng. Syst. Saf. 2002, 76, 255-264. [CrossRef]

108. Sun, H.; Liu, Y.; Tan, J. Research on testing method of oil characteristic based on quartz tuning fork sensor. Appl. Sci. 2021, 11, 5642. [CrossRef]

109. Ahmadi, H.; Mollazade, K. An oil condition monitoring technique to determine the optimal oil type and maintenance schedule. Struct. Health Monit. 2009, 8, 331-339. [CrossRef]

110. Brunner, A.J. Structural health and condition monitoring with acoustic emission and guided ultrasonic waves: What about long-term durability of sensors, sensor coupling and measurement chain? Appl. Sci. 2021, 11, 11648. [CrossRef]

111. Stellman, C.M.; Ewing, K.J.; Bucholtz, F.; Aggarwal, I.D. Monitoring the degradation of a synthetic lubricant oil using infrared absorption, fluorescence emission and multivariate analysis: A feasibility study. Lubr. Eng. 1999, 55, 42-52.

112. Lin, D.; Banjevic, D.; Jardine, A.K.S. Using principal components in a proportional hazards model with applications in conditionbased maintenance. J. Oper. Res. Soc. 2006, 57, 910-919. [CrossRef]

113. Du, L.; Zhe, J. A high throughput inductive pulse sensor for online oil debris monitoring. Tribol. Int. 2011, 44, 175-179. [CrossRef]

114. Xia, Y.; Huo, H. Oil monitoring methods based on information theory. J. Harbin Inst. Technol. (New Ser.) 2009, 16, 396-401.

115. Mackos, N.; Baybutt, M.; Palmer, C.A.; Tario, J.D. Providing embedded, in-situ oil quality monitoring for improved maintenance and on-board diagnostics in trucking and automotive applications. SAE Int. J. Commer. Veh. 2009, 1, 260-267. [CrossRef]

116. Zhang, Q.; Besseville, M.; Benveniste, A. Early Warning of Slight Changes in Systems and Plants with Application to Condition Based Maintenance. [Research Report] RR-1750. INRIA, 1992. Available online: https://hal.inria.fr/inria-00076990/document (accessed on 10 December 2020).

117. Baum, R.L.; Godt, J.W. Early warning of rainfall-induced shallow landslides and debris flows in the USA. Landslides 2010, 7 , 259-272. [CrossRef]

118. Azab, E.; Nafea, M.; Shihata, L.A.; Mashaly, M. A Machine-learning-assisted simulation approach for incorporating predictive maintenance in dynamic flow-shop scheduling. Appl. Sci. 2021, 11, 11725. [CrossRef]

119. Calabrese, F.; Regattieri, A.; Bortolini, M.; Galizia, F.G.; Visentini, L. Feature-based multi-class classification and novelty detection for fault diagnosis of industrial machinery. Appl. Sci. 2021, 11, 9580. [CrossRef]

120. García-Escudero, L.A.; Duque-Perez, O.; Morinigo-Sotelo, D.; Perez-Alonso, M. Robust condition monitoring for early detection of broken rotor bars in induction motors. Expert Syst. Appl. 2011, 38, 2653-2660. [CrossRef]

121. Wang, W.; Zhang, W. Early defect identification: Application of statistical process control methods. J. Qual. Maint. Eng. 2008, 14, 225-236. [CrossRef]

122. Myers, B.K. Designing Dam Safety Monitoring and Early Warning Systems Using Failure Modes Analysis. Available online: http://www.engineeredmonitoringsolutions.com/Designing_Dam_Safety_Using_Failure_Modes_Analysis.pdf (accessed on 10 December 2020).

123. de Smidt-Destombes, K.S.; van der Heijden, M.C.; van Harten, A. On the availability of a k-out-of-N system given limited spares and repair capacity under a condition based maintenance strategy. Reliab. Eng. Syst. Saf. 2004, 83, 287-300. [CrossRef]

124. Birkner, P. Field experience with a condition-based maintenance program of 20-kV XLPE distribution system using IRC-analysis. IEEE Trans. Power Deliv. 2004, 19, 3-8. [CrossRef]

125. Jin, L.; Horikoshi, Y.; Suzuki, K. Optimality of k-out-of-n systems for condition monitoring maintenance using dependent information. Qual. Technol. Quant. Manag. 2006, 6, 132-141.

126. Balakrishnan, N.; Beutner, E.; Kamps, U. Order restricted inference for sequential k-out-of-n systems. J. Multivar. Anal. 2008, 99, 1489-1502. [CrossRef]

127. de Smidt-Destombes, K.S.; van der Heijden, M.C.; van Harten, A. On the interaction between maintenance, spare part inventories and repair capacity for a k-out-of-N system with wear-out. Eur. J. Oper. Res. 2006, 174, 182-200. [CrossRef]

128. Zhou, X.; Xi, L.; Lee, J. Reliability-centered predictive maintenance scheduling for a continuously monitored system subject to degradation. Reliab. Eng. Syst. Saf. 2006, 92, 530-534. [CrossRef]

129. Long, J.; Shenoi, R.A.; Jiang, W. A reliability-centred maintenance strategy based on maintenance-free operating period philosophy and total lifetime operating cost analysis. J. Aerosp. Eng. 2009, 223, 711-719. [CrossRef]

130. Furch, J. Design of operational vehicle maintenance programme based on life cycle cost and reliability centred maintenance. Adv. Mil. Technol. 2009, 4, 37-53.

131. Jia, X.; Christer, A.H. A prototype cost model of functional check decisions in reliability-centred maintenance. J. Oper. Res. Soc. 2002, 53, 1380-1384. [CrossRef]

132. Ali, A.; Chen, Z.; Lee, J. Web-enabled platform for distributed and dynamic decision making systems. Int. J. Adv. Manuf. Technol. 2007, 38, 1260-1270. [CrossRef]

133. Kwon, Y.; Chiou, R.; Stepanskiy, L. Remote, condition-based maintenance for web-enabled robotic system. Robot. Comput. Integr. Manuf. 2009, 25, 552-559. [CrossRef]

134. Marquez, F.P.G.; Schmid, F.; Collado, J.C. A reliability centered approach to remote condition monitoring. A railway point's case study. Reliab. Eng. Syst. Saf. 2003, 80, 33-40.

135. Pedregal, D.J.; Marquez, F.P.G.; Schmid, F. RCM2 predictive maintenance of railway systems based on unobserved components models. Reliab. Eng. Syst. Saf. 2003, 83, 103-110. [CrossRef] 
136. Tiwari, A.; Ballal, P.; Lewis, F. Energy-efficient wireless sensor network design and implementation for condition-based maintenance. ACM Trans. Sens. Netw. 2007, 3, 1-23. [CrossRef]

137. Tiwari, A.; Lewis, F.L.; Ge, S.S. Wireless sensor network for machine condition-based maintenance. In Proceedings of the 8th International Conference on Control, Automation, Robotics and Vision, Kunming, China, 6-9 December 2004; pp. 461-467.

138. Djurdjanovic, D.; Lee, J.; Ni, J. Watchdog Agent-An infotronics-based prognostics approach for product performance degradation assessment and prediction. Adv. Eng. Inform. 2003, 17, 109-125. [CrossRef]

139. Almomani, M.; Abdelhadi, A.; Seifoddini, H.; Xiaohang, Y. Preventive maintenance planning using group technology. J. Qual. Maint. Eng. 2012, 18, 472-480. [CrossRef]

140. Gong, Y.; Guan, L.; Feng, X.; Wang, L.; Yu, X. In-Situ lubricating oil condition sensoring method based on two-channel and differential dielectric spectroscopy combined with supervised hierarchical clustering analysis. Chemom. Intell. Lab. Syst. 2016, 158, 155-164. [CrossRef]

141. Da-Silva, E.; Neto, R.; Assis, L.; Matamoros, E.; Medeiros, J. Study of chemical analysis of oil applying data mining techniques. In Proceedings of the 21st Brasil International Congress and Exhibition, Sao Paulo, Brazil, 2-4 October 2012; pp. 1-8.

142. Wakiru, J.; Pintelon, L.; Chemweno, P.; Muchiri, P. Analysis of lubrication oil contamination by fuel dilution with application of cluster analysis. In Proceedings of the 17th International Scientific Conference on Industrial Systems IS, Novi Sad, Serbia, 4-6 October 2017; pp. 252-257.

143. Yi, S.; Zhao, N.; Li, S.; Xu, Z. A study on fault diagnostic method for the lube oil system of gas turbine based on rough sets theory. In Proceedings of the 11th International Conference on Fuzzy Systems and Knowledge Discovery FSKD, Xiamen, China, 19-21 August 2014; pp. 42-48.

144. Thurston, M.; Lebold, M. Standards developments for condition based maintenance systems. In Proceedings of the 55th Meeting of the Society for Machinery Failure Prevention Technology, Virginia Beach, VA, USA, 2-5 April 2001.

145. Takata, S.; Kimura, F.; van Houten, F.J.A.M.; Westkämper, E.; Shpitalni, M.; Ceglarek, D.; Lee, J. Maintenance: Changing role in life cycle management. CIRP Ann. 2004, 53, 643-655. [CrossRef]

146. Ahmed, S.; Hassan, M.H.; Taha, Z. TPM can go beyond maintenance: Excerpt from a case implementation. J. Qual. Maint. Eng. 2005, 11, 19-42. [CrossRef]

147. Raheja, D.; Llinas, J.; Nagi, R.; Romanowski, C. Data fusion/data mining-based architecture for condition-based maintenance. Int. J. Prod. Res. 2006, 44, 2869-2887. [CrossRef]

148. Banjevic, D.; Jardine, A.K.S.; Makis, V.; Ennis, M. A control-limit policy and software for condition-based maintenance optimization. INFOR 2001, 39, 32-50. [CrossRef]

149. Sundberg, A. Management aspects on condition based maintenance-The new opportunity for maritime industry. In Proceedings of the 9th International Conference on Marine Engineering Systems, Helsinki, Finland, 19-21 May 2003.

150. Campos, J. Development in the application of ICT in condition monitoring and maintenance. Comput. Ind. 2009, 60, 1-20. [CrossRef]

151. DoD CBM + Guidebook' Released May 2008. Available online: https://acc.dau.mil/CommunityBrowser.aspx?id=54711 (accessed on 12 January 2021).

152. CBM Plus, Defense Acquisition University Training. Available online: https://learn.dau.mil/html/clc/Clc1.jsp?cl= (accessed on 14 June 2021).

153. Survey Report, Best Manufacturing Practices, Centre for Excellence. Available online: http://www.bmpcoe.org/bestpractices / internal/arlps/arlps_33.html (accessed on 12 June 2021).

154. The Applied Research Laboratory at the Pennsylvania State University' (ARL Penn State), USA. Available online: http://www. arl.psu.edu/facilities/soa_facilities.html (accessed on 17 June 2021).

155. Condition Based Maintenance, College of Engineering and Computing, USC, USA. Available online: http://cbm.me.sc.edu/ (accessed on 17 June 2021).

156. Condition Based Maintenance Research at University of Toronto, Ontario, Canada. Available online: http://www.mie.utoronto. $\mathrm{ca} /$ research/labs.php?spec=18 (accessed on 20 September 2021).

157. Robotics Research Group' at 'Univ. Texas at Austin'. Available online: http://www.robotics.utexas.edu/rrg/research/conditionb / (accessed on 10 June 2020).

158. Centre for Operational Research and Applied Statistics (CORAS) of University of Salford, Greater Manchester University. Available online: https://www.mams.salford.ac.uk/CORAS/Research/Operations_Strategy/condition-based-maintenancemodelling.php (accessed on 17 July 2020).

159. Roemer, M.J.; Ge, J.; Liberson, A.; Tandon, G.P.; Kim, R.Y. Autonomous impact damage detection and isolation prediction for aerospace structures. In Proceedings of the 2005 IEEE Aerospace Conference, Big Sky, MT, USA, 5-12 March 2005; pp. 3592-3600.

160. Gu, J.C.; Liu, C.H.; Chou, K.Y.; Yang, M.-T. Research on CBM of the intelligent substation SCADA system. Energies 2019, $12,3892$. [CrossRef] 